\title{
A comparison of teacher and lecturer perspectives on the transition from secondary to tertiary mathematics education
}

\author{
Ye Yoon Hong, Suan Sunandha Rajabhat University, Thailand \\ Suzanne Kerr, Auckland Girls Grammar School, Auckland, NZ \\ Sergiy Klymchuk, AUT University, Auckland, NZ \\ Johanna McHardy, Mount Albert Grammar School, Auckland, NZ \\ Priscilla Murphy, Manukau Institute of Technology, Auckland, NZ \\ Sue Spencer, Epsom Girls Grammar School, Auckland, NZ \\ Michael O.J. Thomas, The University of Auckland, Auckland, NZ \\ Peter Watson, AUT University, Auckland, NZ
}

\begin{abstract}
The transition from school to tertiary study of mathematics comes under increasing scrutiny in research. This article reports on some findings from a project analysing the transition from secondary to tertiary education in mathematics. One key variable in this transition is the teacher or lecturer. This article deals with a small part of the data from the project - analysing secondary teachers' and lecturers' responses to questions on the differences they perceive between school and university and the importance of calculus, a bridging content. The results provide evidence of similarities and differences in the thinking of teachers and lecturers about the transition process. They also show that each group lacks a clear understanding of the issues involved in the transition from the other's perspective, and there is a great need for improved communication between the two sectors.
\end{abstract}

Keywords: transition; teacher; lecturer; secondary; tertiary; university; mathematics education

\section{Introduction}

Growing interest in the transition period from school to university has been fuelled by concerns about decreasing numbers of students opting to study mathematics at university and beyond (e.g. the ICMI Pipeline Project), and their apparently decreasing levels of competence [1]. Serious concern was expressed in the report Tackling the mathematics problem commissioned by the London Mathematical Society [2], surrounding a lack of essential technical facility, a marked decline in analytical powers, and a changed perception of what mathematics is especially with regard to the place of precision and proof. This is not restricted to 'new undergraduates' who 10 years ago would not have proceeded to higher education. The problem is more widespread with concern over the possibility of a widening gap 
shown by studies in different countries around the world, e.g. [3,4]. In addition, it is not just the case that some students are less well prepared, but many 'high-attaining' students may be lacking in fundamental notions of the subject.

Possible problems in the transition from secondary to tertiary education have been recognized for some time, with de Guzman et al. writing that ' $\ldots$ the secondary-tertiary transition can be seen as a major stumbling block in the teaching of mathematics' [5, p. 748]. It seems that although mathematics in elementary and high school enjoys a special position in the curriculum, the knowledge and skills of incoming university students may not echo this fact [6]. One possible reason for this is that a number of changes occur in the transition to tertiary education, including those in teaching and learning styles, type of mathematics taught, conceptual understanding, procedural knowledge required to advance through the material, and changes in the amount of advanced mathematical thinking needed. The amount of research in mathematics education at the tertiary level is still modest [7], and does not adequately cover the secondary-tertiary transition. However, a review of the literature that exists produces ample evidence that the transition in mathematics is a complex problem [5,8-11]. Further, researchers writing on the transition period from school to university education in mathematics also indicate that the mathematical under-preparedness of students entering university is an issue [12-15], and that this may impact on students' success in university mathematics [16,17], although not all studies agree on this [4]. One specific problem relates to students' procedural understanding of algebraic material $[18,19]$. Such studies mention a number of possible reasons for student under-preparedness, such as a recent trend of moving from elite to mass university education, lowering the mathematics standards at school and university, inadequate funding, etc.

While not wishing to prejudice research outcomes, our framework is built around the hypothesis that there may be qualitatively different approaches to mathematical thinking at school and tertiary levels. A developing theory by Tall [20,21] suggests that the mathematical thinking exists in three worlds, the embodied, symbolic and formal. The embodied is where we make use of physical attributes of concepts, combined with our sensual experiences to build mental conceptions. The symbolic world is where the symbolic representations of concepts are acted upon, or manipulated, where it is possible to switch from processes to do mathematics, to concepts to think about mathematics. The formal world is where properties of objects are formalized as axioms, and learning comprises the building and proving of theorems by logical deduction from these axioms. If tertiary courses are trying to build thinking in the formal world with students who are primarily symbolic thinkers, then difficulties will arise. Researchers such as Ball [22] and Ma [23] have argued that a deeper understanding of why mathematical ideas work rather than just how they are carried out is crucial to retention and long-term understanding. In addition, many students are exposed to a formal deductive approach in mathematics for the first time on entry to university and may therefore experience a significant amount of cognitive conflict in their first year [24,25]. In this article we examine teachers' and lecturers' views on some of the transition issues described above. The main research questions addressed were: How do teachers and lecturers perceive student transition from school to university calculus?; and What do they see as the dominant issues influencing this transition? 


\section{Method}

This study is part of a larger research project entitled 'Analysing the Transition from Secondary to Tertiary Education in Mathematics' involving teachers, lecturers and students, which employs questionnaires, interviews and teaching observations. A questionnaire was sent to all 350 secondary schools and 31 tertiary institutions (polytechnics, universities, wanangas and institutes of technology) in New Zealand to be completed by all teachers who teach calculus in Years 12 or 13 (age 17-18 years) and by all the lecturers who teach calculus or teach in various courses that have calculus components. The questionnaire was posted, complete with a stamped addressed return envelope, and teachers and lecturers were given three weeks to answer. After this a follow-up copy was sent by email to remind the teachers and lecturers to reply. Using this approach we received a total of 178 teacher and 26 lecturer responses, and some of these were interviewed. There are no figures available on the total number of calculus teachers and lecturers in the schools/institutions, which vary in size from fewer than 30 students (small country school, polytechnics, wanangas and institutes of technology) to 3000 (inner city and universities), but we estimate the response rate at about $30 \%$ of the school/tertiary population. In this article we present and compare the teachers' and lecturers' responses to two questions from the questionnaire and some Likert-style questions, along with some interview comments. Of the 178 teachers and 26 lecturers who responded to the survey, only 154 teachers (82 male and 79 female) and 23 lecturers (19 male and 4 female) gave personal demographic details. Of these $55 \%$ of the teachers had taught for more than 11 years, compared with only $17 \%$ of the lecturers.

\section{Results}

In Q22 of the survey, teachers and lecturers were asked if they thought that there were differences between Year 13 and first year tertiary calculus teaching in the following areas: A - assessment, B - teaching style, C - teaching resources, D teaching emphasis, E - technology use, F - teacher preparedness and G - students' experiences, and if so, why. An overview of the responses is summarized in Figure 1. In each of these areas fewer than $10 \%$ of the teachers responded that there was no difference. While more than $30 \%$ of the teachers perceived differences in assessment, teaching style, teaching resources and student experiences, only teaching style reached over $50 \%$ agreement, and easily the most common response to whether there are any differences was 'don't know'. This could be of concern when considering the transition from school to tertiary study since it implies a lack of knowledge of the tertiary situation. Three teachers alluded to the possible reason for this in their interviews:

I think that we don't ... we haven't got a lot of uniformity amongst schools in presenting to students what to expect at university, and I don't think the universities do that brilliant a job in feeding back to schools what they want ... I do believe that, where schools are trying to find out what's required at university. (T018)

I think it would be really useful from my point of view to actually meet with a lot of the people who get our students, and say to them 'what are the things that we are doing that are really good and what are the things that you would like us to do more of?' (T010) 


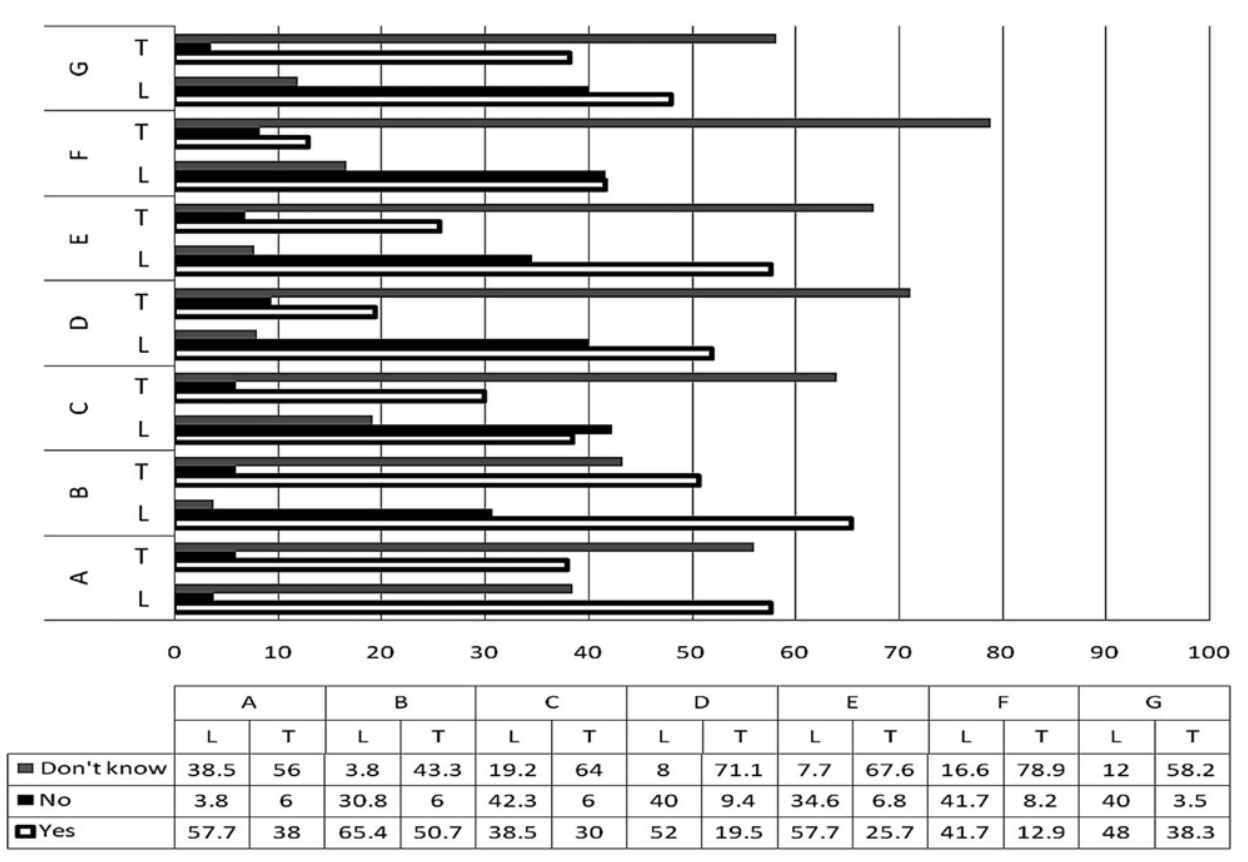

Figure 1. A comparison of teachers’ and lecturers’ percentage responses for Q22.

I wouldn't know. The task of a secondary school is to follow the curriculum. Occasionally I would divert and teach something slightly different, beyond the curriculum, but I don’t do it often. (T146)

A majority of the lecturers (450\%) perceived differences in assessment, teaching style, technology use and teaching resources, with close to this (48\%) in student experiences. They were equally split on $41.7 \%$ about whether there were differences in teacher preparedness. We assume that the $38.5 \%$ who did not know whether there was a difference in assessment implies a lack of knowledge of the school assessment system by lecturers, because many have not taught in schools, or have not taught to the recently introduced National Certificate in Educational Achievement (NCEA) assessment system. However, they did seem to have a reasonable knowledge of the situation regarding technology, teaching style and teaching emphasis, since their 'don't know' percentages were considerably lower than the teachers'. We will now consider each of the areas $A-G$ in more detail.

\subsection{Assessment}

Overall there was no significant difference between the number of teachers and lecturers who answered that there were differences in assessment $\left(x^{2} 1 / 43.55, p 50.1\right)$. Teachers who went on to comment about differences in assessment between school and tertiary level made observations such as, 'A lot more assessment' (4, 6.1\% of 66 comments), although it is not clear whether they felt that school or tertiary had more. References were made to the differences in assessment styles, such as 'Standardsbased versus norm-referenced' $(4,6.1 \%)$ and 'Presumably universities are not using the type of marking used in NCEA [national] exams' (2, 3.0\%). There were a few 
comments about the use of technology in assessment: 'Emphasis on no calculator use in tertiary calculus' (2, 3.0\%); and 'University has computer lab sessions and assignments done using computers'. There were also interesting differences in the perception of relative difficulty, 'Easier to achieve at a top level at university than at NCEA level 3'; 'University level is a bit more challenging'; and 'Some topics requiring higher skills and extra topics such as matrix and learning how to solve using Matlab'. In their interviews teachers talked at length about the NCEA assessment and the attitudes of students and themselves in dealing with this summative assessment. A theme of tailoring work to assessment at a specific, often lower, level was prevalent: 'The type of questions I give them is similar to that they will receive in an exam or an assessment' (T145); 'I think that the internal assessments ... because you know what you're going to be assessing them and because of time constraints, you can teach the content that's in the assessment. I'm afraid that that's the sort of thing that has crept in' (T156); and 'Let me think of an example, let us go back to my expectations with the majority of the class, if I'm aiming at achieved or merit I might skip out the excellence part work at the end' (T134).

In contrast, some lecturers presented a vague understanding of school assessment in terms of the type and how they are graded when comparing with tertiary practice: 'No assignments at school' (L1); 'Must pass regular basic skills test (without crib sheets etc.) and finals examining a broad range of topics' (L4); and 'Formal exams' (L5). On the other hand other lecturers were clearly aware of the NCEA school system, and were able to make comparisons: 'NCEA does not require a student to get 'more than half' correct to pass (achieve)' (L10); 'Assignments differ from NCEA internal assessments' (L3); and 'Not so vigorously 'standard based'. Marks are given for partial and partially correct answers' (L11). In terms of grading, these statements by L10 and L11 may suggest that the lecturers perceived students achieve a lower level of performance because of the standards-based marking in NCEA examinations, whereas at tertiary level they expect all working to be shown to pass the examination, and students gain credit for all they do.

\subsection{Teaching style}

While there was no significant difference between the number of teachers and lecturers who thought that there were differences in teaching style $\left(x^{2} 1 / 41.93\right.$, n.s.), there were significantly more teachers than lecturers who said that they did not know whether there were any differences $\left(x^{2} 1 / 414.74\right.$, p 5 0.001). The prevalent perception of differences in teaching styles was that the level of interaction between lecturers and students at tertiary level is not sufficient (41 teachers, $64.1 \%$ of 64 responses; 10 lecturers, $80 \%$ of 13 responses). The lecturers' comments included 'Primarily lecture format less interactive than school' (L2) and 'Teaching style more formal less individualistic' (L3). That this is seen as due to large class size is evident from comments such as 'my class is 420 students! Determine style' (L8) and 'Lecture style is all one way for large 200+ classes' (L13). These comments are consistent with many teachers' comments such as 'Tertiary students are taking more responsibility for their own learning. Teaching style is more teacher-centred' and 'less personal interaction with students', but this was also tempered with: 'Attendance at tutorials at university may alleviate or moderate the 'clinical' nature of lecturing'; 
'Large course sizes at university prevent interactive investigative approach to new material. Difficult for students to ask questions'; and 'more lecturing rather than teaching'. Other observations included, 'Teaching is more detailed in Year 13 than in the first year tertiary calculus' and 'more technology and lecturing' at tertiary level. Teachers indicated that the communication between themselves and the students was of paramount importance to them, and there were many comments in the interviews supporting that.

\subsection{Teaching resources}

The perception of the teachers $(20,64.5 \%$ of 31 responses) was that tertiary institutions have far more resources than secondary schools. While there was no significant difference between the number of teachers and lecturers who thought that there were differences in teaching resources $\left(x^{2} 1 / 40.73\right.$, n.s.), once again there were significantly more teachers than lecturers who said that they did not know whether there were any differences $\left(x^{2} 1 / 418.16, p 50.001\right)$. Examples of differences given by teachers included: CD resources, textbooks and access to computers. 'Universities usually have much better computer resources' enabling 'Mostly technology based' courses (2, 6.5\% of 31 responses) and 'A lot of good clearly explained textbooks'. The access to appropriate resources to explain or illustrate a particular idea or concept is a necessary feature of an effective mathematics lesson whether it is at a secondary or tertiary level. Teachers and lecturers need to have the time, the will and the opportunity to investigate, learn or create such resources. However, the interviews predominantly highlighted that availability of time was the greatest resource lacking in schools. Second to this was the lack of resources such as computers and software. Those lecturers who perceived differences supported the teachers' perception, saying that 'we have good computer resources' due to 'more reliance on computers' in their teaching. One lecturer considered there was less varied use of resources, since 'at university we tend to only use lecture handouts and a textbook.' While the majority of the lecturers (42\%) did not perceive any differences with the schools in terms of resources, some stated that at tertiary level there is 'less reliance on textbook in some courses' although they use 'different textbooks' in other courses. It appears that lecturers have more flexibility in their curriculum and tend to use a variety of resources, but are not as aware of the differences with the schools as teachers are.

\subsection{Teaching emphasis}

There were significantly more lecturers than teachers who thought that there were differences in teaching emphasis $\left(x^{2} 1 / 412.53\right.$, p 5 0.001). However, it is interesting that $71.1 \%$ (of 149 responses) of the teachers answered that they did not know of any differences in teaching emphasis between school and tertiary level, significantly more than the number of lecturers who said they did not know $\left(x^{2} 1 / 436.3, p 50.001\right)$. Those who commented mostly felt there was greater depth to understanding (2, $11.1 \%$ of 18 responses), an emphasis on the theory, and a more formal approach $(2,11.1 \%)$ at tertiary level than at Year 13 . Some felt there were 'Different approaches to certain sections, inclusion/exclusion of topics at school' (2, 11.1\%), and 'more on pure mathematics (and) less on applications'. One teacher spoke at 
length in a negative way about the change in emphasis to practical contexts with the introduction of NCEA assessment:

... students who are less capable struggle to understand maths unless they can fit it into a practical situation then everything we do needs to have a direct link to a practical situation, and that isn't mathematics in my view ... If we keep on going this way ... then we'll actually lose what mathematics offers, because it will become so simplistic ... And that's scary for me, that it's all going that way, that we're getting out of the theoretical mathematics. (T159)

Similarly, $52 \%$ of the lecturers perceive differences that are in tandem with the teachers' view that the lecturers 'focus on understanding concepts rather than learning techniques' and place an emphasis 'on applications in particular areas, example engineering, science'. In the survey, lecturers were asked what they consider important $\left(1 \frac{1 / 4}{4}\right.$ Not important to $5 \frac{1}{4}$ Very important) when teaching calculus. In particular, results showed that $92 \%$ (rating 4 or 5 ) value the learning of concepts and applications in calculus teaching (although only $40 \%$ valued new applications). Further, $88 \%$ thought students should gain problem solving skills, $76 \%$ that they should enhance mathematical thinking skills and $72 \%$ that students should both do exercises from the manual and see the practical value of calculus. On the other hand, only $28 \%$ thought it is important that students work together, $36 \%$ that they should develop communication skills, $44 \%$ valued factual, procedural or algorithmic techniques and $48 \%$ thought that students should gain modelling skills. These results seem to support the contention that concepts, mathematical thinking, applications and problem solving are seen as more important at tertiary level than procedures, modelling, collaboration and communication. In contrast this latter group is often what is emphasized in schools.

\subsection{Technology use}

There were significantly more lecturers than teachers who thought that there were differences in technology use $\left(\mathrm{x}^{2} 1 / 410.70, \mathrm{p} 50.01\right)$, and significantly more teachers than lecturers who said that they did not know whether there were any differences $\left(x^{21} 1 / 433.56, p 50.001\right)$. Those teachers who commented about the use of technology, e.g. computers, PowerPoint, Matlab, and projectors (17, 50\%) considered the tertiary use of technology to be much greater than that of Year 13 teachers, except for the use of graphic calculators (GCs): 'GC is not used at university' (6, 17.6\%); 'Tertiary - also online access of notes, assignments, use computer programs' (2, 5.9\%); 'Vast resources' (2, 5.9\%). This could possibly be due to the curriculum requirements in each case. The main discussion areas in the interviews were about the lack of access to computers, the increasing use of data projectors (PowerPoint) in school teaching and the use of graphic calculators. A concern about a lack of understanding when using the graphic calculator was also discussed:

My belief is that in calculus or senior mathematics we are trying to help them become analytical thinkers ... I think that calculators are undermining what I'm trying to get through in a subject like calculus. (T159)

I haven’t personally used a lot of technology apart from calculators, partly because of difficulty in getting time on the computers. Programmable calculators allow the students to do problems that they don't really understand. (T145) 
The technology I use is: data projector, I use the overhead projector, we've got the graphics calculators, computers for generating simulations and - yeah the [inter]active whiteboard is in my room but so far I haven't learnt how to use it. (T010)

It [technology] has a significant role in teaching and learning and I have some reservations about the use of technology in assessments, because I am concerned that technology can mask real knowledge. (T146)

The teacher point of view that there is greater access to, and use of, technology at tertiary level was echoed by $57 \%$ of the lecturers, depending on their courses. The results from question 12 of the survey served to reiterate the importance of technology in their teaching, with the majority of the 23 lecturer respondents, having used technology such as a computer $(20,83.3 \%)$, a scientific calculator $(10,41.7 \%)$, a graphic calculator $(6,25 \%)$ or computer algebra system (CAS) $(5,20.8 \%)$. The responses of the teachers seem to reflect an acceptance of the reality of the secondary situation and yet a concerted effort to change that reality has the potential to not only change the way mathematics is taught and potentially enjoyed in secondary schools but also to assist with the transition.

\subsection{Teacher preparedness and support for teachers}

While $78.9 \%$ of the teachers claimed to be unaware of any differences in teacher preparedness or support, lecturers were equally split, with $41.7 \%$ perceiving differences and the same percentage no differences. However, this means that there were significantly more teachers than lecturers who were not aware if there were differences $\left(x^{2} 1 / 438.19\right.$, p 5 0.001). In the teacher interviews, the teachers discussed this topic at length, with the predominant issue being time and workload particularly administrative workload. 'If you're tired and you're wrapped off your feet because you're doing your reports and ninety thousand other things.., you don't prepare.' (T156); 'My workload definitely affects the way I teach.' (T018) and 'The workload affects my teaching to the extent that I'm not entirely happy with the quality of teaching I've been able to do' (T010). One of the key determinants of having the energy to prepare well was the issue of classroom management and student control. 'Preparation time; behaviour of the students and the lack of respect... A lot of your class time is spent on managing class' (T145); and '... the teaching time is just about 5 or 10 minutes during a period, and the rest is spent on giving them some tasks that they have to do on their own just to keep them quiet' (T122).

The teachers believe that tertiary lecturers have more time to prepare and also more time to work together at departmental level. 'Possibly more support/ preparedness at university and perhaps time'; 'University has more access to support for resource preparation'; 'More colleagues and departmental discussion at university. Less pedagogy-driven and more mathematics-driven at university'. Some of these views were similar to the lecturers' perception that they are more prepared 'from the point of view of knowledge of subject' (L4). One possible reason cited was 'most students have less access to teachers' (L8). Hence, the lecturers tend to have more time 'to produce and use more of our own resources' (L9). The lecturers also echo the teachers' frustration with their lack of preparedness due to classroom management and heavy workload: 'High school teachers are generally very underprepared for their classes compared with tertiary teachers. They are often discouraged by the impossible situations which they face in the classroom' (L10). 
Contrary to the teachers' opinion that lecturers get more professional development, the lecturers thought they were lacking professional development as 'Most teachers [lecturers are] left to design [their] own, little professional development.' While the reasons for this lack of professional development in the tertiary sector is not known it is a somewhat surprising omission.

\subsection{Students' experiences}

Forty-eight per cent of the lecturers saw differences in students' experiences for similar reasons to $38.3 \%$ of the teachers, although there was no significant difference $\left(x^{2} 1 / 40.83\right.$, n.s.) between the numbers. However, there were significantly more teachers $\left(x^{2} 1 / 418.10\right.$, p 50.001$)$ who said that they did not know whether there was any difference. Among the teachers there was a perception that there is more teacher-student interaction at school $(25,58.1 \%)$ than at tertiary level, but students are less motivated, supported by the following comments: 'Closer teacher/student relationship at school'; 'Suspect that teacher-student communication would be considerably less at tertiary level'; 'More self-motivated in university'; and 'Tertiary students studying maths are usually more motivated than Y13 students' (10, 23.3\%). The view was expressed that 'lecturers don't need to take responsibility for their students' results but secondary school teachers see their role as supporting students through the learning process and giving them opportunities to revisit work'. In contrast, one lecturer argued that the motivation level could be affected when '[Tertiary] students have less individual interaction with lecturers and tutors (only one tutorial per week) [hence] less support and accountability. [It's] easy for students to lack motivation and do nothing'. Another suggested that students 'require [their] own knowledge of study habits'. It appears that both groups see tertiary students as more independent in terms of their learning, and hence taking more responsibility for it, but whether this increases motivation is disputed.

\subsection{Transition}

Following a series of questions to ascertain teachers' perceptions about the differences between Year 13 and first year tertiary calculus, teachers were specifically asked if they thought students had problems moving from school to tertiary calculus, and what could be done to make the transition smoother. Only $25.3 \%$ of the 154 teachers believe there are problems with a similar number (27.3\%) saying that there are none. On the other hand $60 \%$ of the lecturers thought that their students had experienced problems, and this was significantly more than the number of teachers $\left(x^{2} 1 / 410.27\right.$, p 5 0.01). Sixty-nine of the teacher respondents expressed an opinion about how to make the transition easier, along with 14 lecturers. The most often repeated suggestion (from 10\% of the 69 teachers) was that 'Students should aim higher to get merit or excellence as the tertiary education assumes they have a sufficient knowledge of Yr 13 calculus'. It appears that these teachers observe students simply aiming to 'pass' rather than understand at a deeper level. Related to this is the observation that 'Study skills and self-discipline is the main requirement'. Thus, they suggest that a mediocre pursuit of academic achievement in school could possibly be a plausible reason why students have problems in the transition period. One lecturer also suggested that it would 'depend on how well they have been taught 
at school - some students come very well prepared and handle the transition well. Others are less well prepared' (L4). The result may be a 'lack of confidence with basic skills, powers, brackets, fractions, quadratics and trigonometry' (L6). The following two comments by teachers illustrate the view that problems may be faced by both poorly- and over-prepared students: 'If calculus is well taught at school, the first year of university calculus can be "too easy",'; and 'Only if it were properly taught at school first year university mathematics is sometimes easier than L3 maths and there is little challenge for the top students in first year. As a consequence, second year exams are a bit of a shock'.

Another possible problem faced by the students is the low level of lecturerstudent interaction. Nearly $9 \%$ of the 69 teachers commented that the amount and quality of interaction between lecturers and students was a problem, mentioning 'they don't get as much one-to-one contact and help'. Linked to this is the perceived difference between teaching styles at school and university. Respondents thought one of the difficulties for students is that the sheer quantity of information given in a lecture situation, with insufficient time to understand properly: 'I think students are used to understanding before moving onto the next topic. In a lecture, the quantity is greater so they just copy instead of trying to understand what's being taught'. One teacher suggested that lecturers needed to change their approach: 'Train lecturers to organize material and have better understanding of student knowledge'.

Interestingly, $7 \%$ of teachers responding believe that more communication between school and university would ease the transition for students. However, one teacher was unconcerned about this: 'The transition is a change of learning cultures from hands-on to hands-off - all part of the learning curve'. Lecturers also suggested ways to ease the transition, including 'smaller tutorials with more emphasis on student problem solving' (L14), expecting 'students taking responsibility for their own learning' (L5) and not rushing 'students to learn or cope with the change in teaching style and be more independent. It is a gradual process’ (L7).

\subsection{Student preparedness and importance of calculus}

In addition to Q22, a five-point Likert scale (1 1/4 strongly disagree, $5 \frac{11 / 4}{\text { strongly }}$ agree) asked teachers to rate how well prepared their students are for further study in mathematics (positive response corresponding to students being well prepared). A comparative analysis of the teacher and lecturer mean responses for Qs 1, 4, 6, 11, 16, 18 and 19 is shown in Figure 2. In general, the teachers had higher mean responses for all the questions, except Q1 and Q11. For Q6, the teachers mean score was 3.91, indicating they mostly felt that their students are well prepared for further study, whereas lecturers tended to disagree slightly (2.29). Teachers were asked (Q19) to rate the importance of calculus in the real world (a higher score corresponding to calculus being important). Here their mean was 3.83, showing that calculus is generally regarded by teachers as being important in society. On the other hand, lecturers consider it to be less important, with a mean score of 2.17 (a significant difference, $x^{2} 1 / 435.70$, p 5 0.001). This result is consistent with question 1 about whether calculus is of little benefit in society (Q1, lecturers 4.17 agree; teachers 1.68 don't, a highly significant difference, $x^{2} 1 / 4105.21, p 50.0001$ ) and NCEA has placed too much emphasis on calculus (Q11, lecturers 3.61). Eighty-six per cent of the 170 teachers and $10 \%$ of the 21 lecturers who responded encourage their students to 


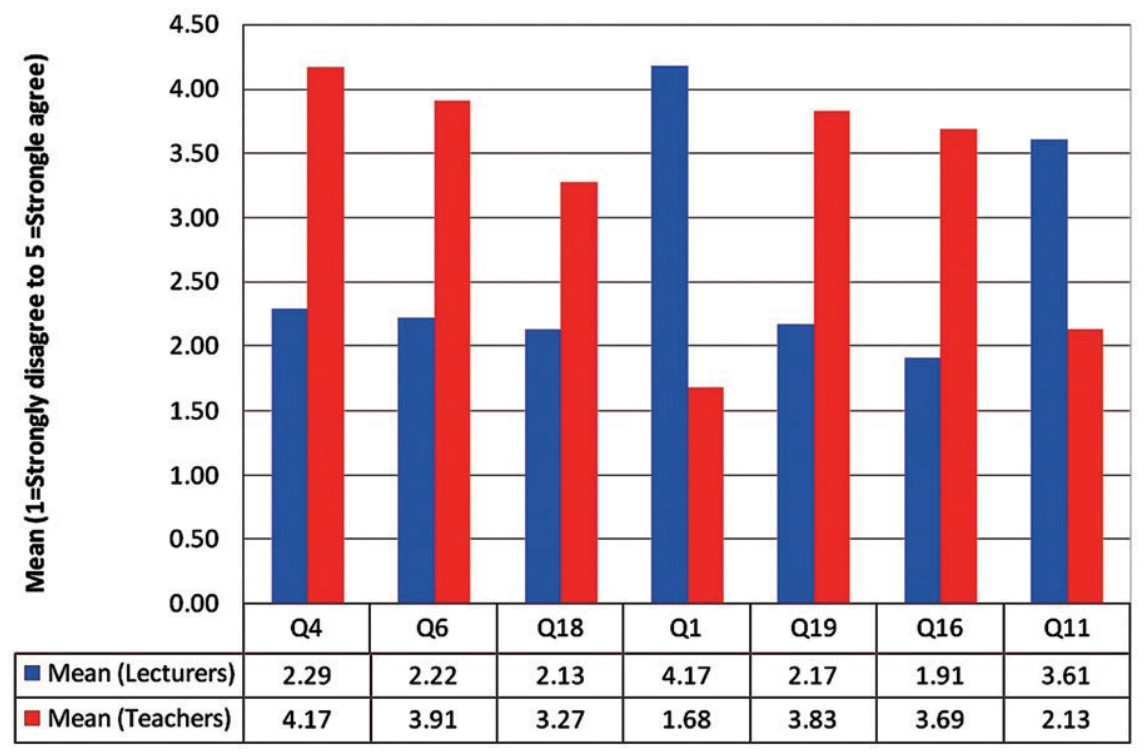

Figure 2. Comparison of means for some teachers' and lecturers' Likert question responses. Q4. I encourage my students to study mathematics further after school/my course/paper; Q6. My students are well prepared for studying further calculus after school/my course; Q18. Calculus is taught differently at tertiary level from school; Q1. Calculus is of little benefit in society; Q19. Calculus is of major importance in the real world; Q16. I consider calculus as a core course in my students' programme; Q11. NCEA Level 3/my teaching programme has too much emphasis on calculus.

study mathematics further (a significant difference, $x^{2} 1 / 462.47, \mathrm{p} 5$ 0.001). When it comes to the preparedness of students for post-school study, $65.9 \%$ of the teachers thought that they were well prepared, but only $26 \%$ of the lecturers believed this (a significant difference, $\mathrm{x}^{2} 1 / 413.45, \mathrm{p} 5$ 0.001). Teachers generally do not know what happens at tertiary level, with $60 \%$ (teachers) not knowing whether calculus is taught differently at tertiary level compared with schools and 31\% of them believing it is taught differently. The corresponding figures for lecturers were $17 \%$ (not know) and 9\% (it differs), meaning that significantly more teachers think that there is a difference in teaching $\left(x^{2} 1 / 44.08, p 50.05\right)$. There is apparently a need to educate teachers and lecturers about the differing requirements of school and tertiary calculus.

\section{Conclusions}

In summary, this article compares the teachers' and lecturers' perspectives of calculus teaching and learning in the school-tertiary transition. Both groups perceive some differences between Year 13 and first year tertiary calculus teaching: there is a greater use of technology at tertiary; tertiary institutions are better resourced, particularly in terms of computers and time; there is a more formal approach to tertiary teaching; secondary teachers interact more with their students; secondary teachers spend a large amount of time on administration at the expense of lesson preparation and there is more teaching to the assessment at school due to NCEA. Teachers seem to be 
more concerned about the role of calculators in student learning than lecturers and they saw calculus as important in society, while the lecturers didn't. There seems to be a divide between school and tertiary institutions on what is valued in calculus teaching; the former valuing procedures, modelling, collaboration and communication with students, and the latter emphasizing concepts, mathematical thinking, applications and problem solving.

The availability of resources, the time to learn how to effectively incorporate them into lessons and the opportunity to do so need to be addressed. The use of technology and the role it can play in communicating mathematical ideas can provide a starting point for a dialogue between secondary and tertiary teachers. A common philosophy in this area can assist with the transition.

There was some ignorance expressed, notably by the teachers, and to a lesser extent lecturers, about the calculus teaching of the other group. This may be influencing teachers, who see students having fewer problems with the transition than lecturers do, although they believe that too many students do not aim high enough at school. Understanding the nature and emphases of teaching and learning in the schools and tertiary institutions can help to smoothen student transition. Clearly there are important roles for secondary teachers and tertiary lecturers to play in helping students with their transition. Both teachers and lecturers need to be aware of the necessity to help ease the cognitive conflict [24] faced by students and be more aware of changes, including the shift in mathematical thinking, during the schooltertiary transition. One aspect of increasing this awareness is the need for closer communication between secondary and tertiary teachers, and this was expressed in a majority of teacher responses. However, this interaction will occur only when, according to one lecturer, there is 'greater sharing between the two groups [teachers and tertiary educators] and awareness of what is being done in each other's areas'. We concur and hope to be instrumental locally in helping to bring the two groups closer together to construct common aims. It will require a commitment to professional development from both sectors.

Acknowledgement

We would like to thank the New Zealand Ministry of Education for providing funding through a Teaching and Learning Research Initiative grant, organized through the New Zealand Council for Educational Research, which enabled this research to take place.

\section{References}

[1] A. Smith, Making Mathematics Count, The Stationery Office Limited, UK, 2004.

[2] London Mathematical Society (LMS, 1995). Tackling the mathematics problem. Available at http://www.lms.ac.uk/policy/tackling_maths_prob.pdf (retrieved 6 August 2007).

[3] G. Brandell, K. Hemmi, and H. Thunberg, The widening gap — a Swedish perspective, Math. Edu. Res. J. 20(2) (2008), pp. 38-56.

[4] J. Engelbrecht and A. Harding, The impact of the transition to outcomes-based teaching on university preparedness in mathematics in South Africa, Math. Edu. Res. J. 20(2) (2008), pp. 57-70.

[5] de Guzman, M., Hodgson, B., Robert, A., and Villani, V. (1998). Difficulties in the passage from secondary to tertiary education. Proc. Int. Congr. Mathematicians 3, 747-762. 
[6] M. Artigue, What can we Learn from Research at the University Level? in The Teaching and Learning of Mathematics at the University Level: An ICMI Study, D. Holton, ed., Kluwer Academic Publishers, The Netherlands, 2001, pp. 237-254.

[7] A. Selden and J. Selden, Tertiary mathematics education research and its future, in The Teaching and Learning of Mathematics at the University Level: An ICMI Study, D. Holton, ed., Kluwer Academic Publishers, The Netherlands, 2001, pp. 207-220.

[8] D. Barnard, The transition to mathematics at university: students' views, New Zealand J. Math. 32(Supplementary Issue) (2003), pp. 1-8.

[9] C. McInnes, R. James, and R. Hartley, Trends in the first Year Experience in Australian Universities, AGDS, Canberra, Australia, 2000.

[10] A.H. Schoenfeld, What do we know about mathematics curricula? J. Math. Behav. 13(1) (1994), pp. 55-80.

[11] L. Wood, The secondary-tertiary interface, in The Teaching and Learning of Mathematics at University Level: An ICMI Study, D. Holton, ed., Kluwer, Holland, 2001, pp. 87-98.

[12] M. Hourigan and J. O’Donoghue, Mathematical under-preparedness: the influence of the pre-tertiary mathematics experience on students' ability to make a successful transition to tertiary mathematics courses in Ireland, Int. J. Math. Educ. Sci. Technol. 38(4) (2007), pp. 461-476.

[13] A. Kajander and M. Lovric, Transition from secondary to tertiary mathematics, McMaster University experience, Int. J. Math. Educ. Sci. Technol. 36(2-3) (2005), pp. 149-160.

[14] H.S. Luk, The gap between secondary school and university mathematics, Int, J. Math. Educ. Sci. Technol. 36(2-3) (2005), pp. 161-174.

[15] A. Selden, New developments and trends in tertiary mathematics education: or more of the same? Int. J. Math. Educ. Sci. Technol. 36(2-3) (2005), pp. 131-147.

[16] G. Anthony, Factors influencing first year students' success in mathematics, Int. J. Math. Educ. Sci. Technol. 31(1) (2000), pp. 3-14.

[17] S. D'Souza and L. Wood, Rationale for collaborative learning in first year engineering mathematics, New Zealand J. Math. 32(Supplementary Issue) (2003), pp. 47-55.

[18] A. Kajander and M. Lovric, The double cohort: preliminary research on the transition from secondary to university level mathematics, The Ontario Math. Gazette 42(4) (2004), pp. 33-36.

[19] J. Novotna and M. Hoch, How structure sense for algebraic expressions or equations is related to structure sense for abstract algebra, Math. Educ. Res. J. 20(2) (2008), pp. 93-104.

[20] D.O. Tall, Building theories: the three worlds of mathematics, For the Learning of Mathematics 24(1) (2004), pp. 29-32.

[21] D.O. Tall, The transition to formal thinking in mathematics, Math. Educ. Res. J. 20(2) (2008), pp. 5-24.

[22] Ball, D. (2002) Towards a practice-based theory of mathematical knowledge for teaching, in Proceedings of the Canadian Mathematics Education Study Group Conference, B. Davis and E. Simmt, eds., Kingston, Ontario, pp. 3-14.

[23] L. Ma, Knowing and Teaching Elementary Mathematics, Lawrence Erlbaum, Mahwah, New Jersey, 1999.

[24] Tall, D.O. (1997). From school to university: the transition from elementary to advanced mathematical thinking, in Proceedings of the 7th Conference of the Australasian Bridging Mathematics Network, M. O. J. Thomas, ed., Auckland, New Zealand, pp. 1-20.

[25] S. Stewart and M.O.J. Thomas, Embodied, symbolic and formal thinking in linear algebra, Int. J. Math. Educ. Sci. Technol. 38(7) (2007), pp. 927-937. 